\title{
La Descripción Parnasiana en la Poesía de Rubén Darío
}

$\mathrm{T}$ HÉOPHILE Gautier (1811-1872) representa en Francia la transición entre los dos extremos del romanticismo sensiblero y el parnasianismo impasible. Empezó como un romántico antiburgués y sentimental "au gilet rouge", pero en el fondo Gautier era un pintor. Por lo tanto, vemos en su poesía una evolución desde un contenido manifiestamente subjetivo hacia una representación "objetiva" de belleza plástica, o sea desde la emoción humana hacia la estética. Esta tendencia llega a su culminación en la obra maestra de Gautier Emaux et Camées (1852). Aquí es casi completo el triunfo de la belleza sensorial - especialmente en la visión colorida y brillante-, sobre la idea y el sentimiento. Este aspecto parece ser el fundamental del carácter y de la poesía de Théophile Gautier, tanto como de toda la escuela del arte por el arte; por consiguiente, será este aspecto el que buscaremos en la poesía de Rubén Darío (1867-1916). En este sentido limitado, el fin del presente estudio será averiguar la extensión y la naturaleza de la influencia de Gautier y su escuela en la poesía de Rubén Darío.

Aunque Rubén conocicra desde muy joven las poesías de Gautier, ${ }^{1}$ parece que el influjo de éste fue relativamente poco en sus obras juveniles, es decir, antes de Azul (1888). ${ }^{2}$ Por eso, comenzamos con Azul y nos limitamos, aunque sea arbitrariamente, a los libros organizados por Rubén a partir de Azul, sin tomar en cuenta las poesías dispersas.

Entre las diecinueve poesías de $A z u l$, incluyendo las adiciones de 1890 , hay sólo tres en que puede decirse que el asunto principal sea la descripción de escenas vistas. Son "Invernal", "De invierno" y "Chanson crépusculaire". El poeta, empero, hace un papel activo en las dos prime-

1 Véase, por ejemplo, Erwin K. Mapes, L'influence française dans l'oeuvre de Rubén Darío (Paris, 1925), p.14.

I Ibid., pp. 30-31. 
ras, que son, excepto en su longitud, bastante parecidas: la escena de amor en casa, que contrasta con la noche invernal de fuera. La tercera, escrita en francés, termina en una nota de romanticismo bastante fuerte, que se encuentra en menor grado en varios poemas de Gautier ("Affinités secrètes", "Clair de lune sentimental", "Symphonie en blanc majeur", "La nue"). En las tres, los elementos de color son importantes, pero no son predominantes. Rubén mismo habló de "De invierno" como un "soneto a la francesa y de asunto parisiense". ${ }^{3}$

Entre las dieciséis poesías restantes de $A z u l$, cuatro contienen elementos descriptivos de cierta importancia, pero con pocos o ningunos colores, a saber: "Estival", "Caupolicán", "Walt Whitman" y "J. J. Palma". Las otras doce poesías contienen poquísima descripción, aunque sí varios dispersos toques de color. Un ejemplo destacado de estos toques se ve en "Ananké", al decribirse la paloma:

Mi ala es blanca y sedosa;

la luz la dora y baña

y céfiro la peina.

Son mis pies como pétalos de rosa. ${ }^{4}$

Pero generalmente son elementos escasos y aislados. Ahora veamos Prosas profanas y otros poemas, primero la edición de 1896 y después las adiciones de 1901, cada sección por turno. Entre las dieciocho poesías de Prosas profanas hay seis que son principalmente descriptivas o coloristas: "Era un aire suave. ..", "Divagación", "Sonatina", "Blasón", "Alaba los ojos negros de Julia" y "Bouquet". La primera describe una escena general, pero of rece pocos indicios de color. La segunda, como indica el título, tiene distintas escenas y muchas imágenes diversas, con varias pinceladas de color a través de la obra. La tercera, ostensiblemente una narración, está llena de pequeñas visiones, muchas con color. La cuarta es una descripción fantástica del cisne con bastante color y predominio del blanco. Las dos últimas están plenamente dedicadas al color, la una al negro y la otra al blanco. Aquélla contrasta el color negro con otros colores; la dedicada al blanco, "Bouquet", evoca una serie de cosas blancas, tal como hizo Gautier en "Symphonie en blanc majeur". De hecho, la primera estrofa de "Bouquet" está dedicada a Gautier, donde nombra el poema de éste. Mencionemos también el verso de "Divagación": "Gautier adoraba a las princesas chinas".5

3 Historia de mis libros (Madrid, 1917), p. 179.

4 Poesias completas, ed. Alfonso Méndez Plancarte, 7a. ed. (Madrid, 1952), p. 575 .

5 Ibid., p. 603. 
Además de las seis poesías mencionadas, los dos sonetos "Para una cubana" y "Para la misma" son retratos, aunque haya poca descripción plástica, ${ }^{6}$ especialmente en el segundo. Por el primero sólo sabemos que tiene el rostro blanco y la boca roja.

En las diez poesías restantes hay elementos de descripción en "Del campo", "Canción de carnaval", "El faisán", "Garçonnière", "Heraldos" e "Ite, missa est", pero dispersos y a menudo poco plásticos. En las otras cuatro, salvo "Mía", hay sólo algún leve toque de color. "Mía" no contiene ningún color.

En "Coloquio de los centauros" hay un poco de descripción de vez en cuando, pero los elementos de color son ratísimos.

De las nueve poesías de Variat, hay tres que son principalmente descriptivas: "El poeta pregunta por Stella", "Pórtico" y "Sinfonía en gris mayor". La primera, como "Bouquet", ya mencionada, es otra "sinfonía en blanco". El color es el único interés de la composición y ésta acaba en una nota ligeramente sentimental, como ya notamos que acontece en algunos poemas de Émaux et Camées. La segunda presenta varios aspectos de Andalucia, con frecuentes indicios de color. Según Arturo Marasso, 1a fuente de este poema se encuentra en Voyage d'Espagne de Gautier. ${ }^{7}$ La tercera se parece a la "Symphonie en blanc majeur", sobre todo en el título; pero no es simplemente una serie de cosas dispares que evocan el mismo color, como el poema de Gautier o "Bouquet" y "El poeta pregunta por Stella" de Rubén. En lugar de eso, el color gris es sólo el color predominante de la escena que el poeta describe; el color mismo ya no es el asunto de la poesía, sino sólo un elemento entre otros, aunque quizá sea el más importante.

Entre las otras poesías de Varia, "Elogio de la seguidilla" contiene muchas metáforas en que hay algún elemento de color. Las otras cinco son, en su mayor parte, obras de simbolismo o alegorías que contienen ciertos elementos descriptivos, pero poquísimo color.

En la sección Vierlaine, la primera parte, "Responso", of rece poca descripción, pero la segunda, "Canto de la sangre", es casi una "sinfonía en rojo", con su nuevo tipo de sangre en cada estrofa.

En las dos partes de Recreaciones arqueológicas, "Friso" y "Palimpsesto", hay varias descripciones con algún empleo de colores, pero, sobre todo en la segunda, predomina la narración.

En "E1 reino interior" Rubén emplea mucha coloración en su alego-

a Empleamos los términos "plásticos" y "plasticidad" tanto para lo pictórico como para lo propiamente escultural.

7 Rubén Darío y su creación poética (Buenos Aires, 1954), pp. 108-109. 
ría de los vicios y virtudes. Examinemos ahora las adiciones de 1901. "Cosas del Cid" es un relato anecdótico con poca descripción, pero desde los primeros versos de la composición se introducen elementos aislados de belleza visual. He aquí el comienzo:

Cuenta Barbey, en versos que valen bien su prosa, una hazaña del Cid, fresca como una rosa, pura como una perla. 8

De los siete Decires, layes y canciones, dos son más que nada descripciones de escenas vistas: "Canción" y "Copla esparça". El color es importante en ambos. Las dos primeras estrofas de "Otro decir" no son una descripción, pero expresan una serie de colores, la segunda por medio de piedras preciosas. Los otros cuatro poemas de esta sección muestran muy poca plasticidad. Sin embargo, la primera estrofa de "Loor" es sumamente interesante:

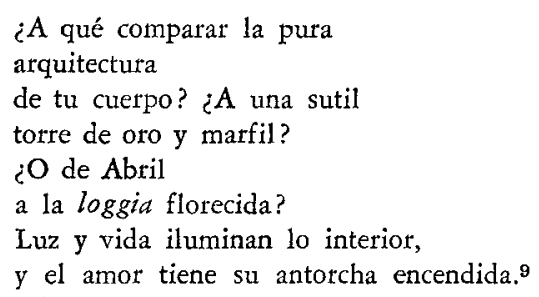

En Las ánforas de Epicuro, dos de los trece poemas son descripciones: "La espiga" y "La gitanilla". El color desempeña en ellos un papel importante. Los otros once poemas muestran algunos de los acostumbrados toques de color y joyería.

Pasamos ahora a Cantos de vida y esperanza, los cisnes y otros poemas (1905). Entre las catorce poesías de Cantios de vida y esperanza, hay sólo una de pura descripción, "Marcha triunfal", y la mayor parte de ésta no es visual sino auditiva. De vez en cuando hay toques de color, tanto en los sonidos, por sinestesia, como en lo visto, pero dista mucho de ser el elemento predominante.

En las otras trece hay sólo algunos toques de color, tal vez menos que antes porque los asuntos parecen más graves. El caso más notable es el de la primera estrofa de "Helios":

\footnotetext{
8 Poesías, p. 663.

9 Ibid., pp. 670-671.
} 
y en el azul sereno

con sus cascos de fuego dejan huellas de rosa. ${ }^{10}$

También en "Pegaso" hay otra imagen equina, pero aquí la metáfora es simbólica:

domador del corcel de cascos de diamante,

voy en un gran volar, con la aurora por guía,

adelante en el vasto azur, isiempre adelante!11

Así se ve cómo Rubén combina elementos de belleza plástica con un asunto abstracto.

En los cuatro poemas de Los Cisnes hay más simbolismo que plasticidad, aunque el autor se refiera a veces a su color:

¡oh blancas urnas de la armonia!

Ebúrneas joyas. . :12

Entre los cuarenta y un Otros poemas, hay cinco en que es preponderante la descripción: "Retratos", "Tarde del trópico", "Leda", "Marina" y "A Goya". El primero consiste en la descripción de dos retratos. La representación es gráfica y colorida, pero el autor no se limita a la apariencia física. "Tarde del trópico" es pura descripción, pero hay mucho más para el oído que para la vista. Las dos primeras estrofas de "Leda" son una descripción muy colorida del cisne; las dos últimas son parcialmente narrativas. "Marina" es esencialmente una descripción algo fantástica del mar, con empleo moderado del color. "A Goya" consiste en visiones de los cuadros de Goya, y según Marasso está inspirado, como "Póttico", en Voyage d'Espagne.13 Hay unas pocas notas de color.

De las treinta y seis poesías restantes, hay elementos descriptivos de cierta importancia secundaria en seis: "Por el influjo de la primavera", "Cleopompo y Heliodemo", "En el país de las Alegorías", "Aleluya!", "Urna votiva" y "Allá lejos".

Como de costumbre, las demás treinta poesías sólo contienen elementos plásticos muy dispersos, por ejemplo en "Un soneto a Cervantes":

10 Ibid., p. 706.

11 Ibid., p. 701.

12 Ibid., p. 717.

13 Op. cit., p. 269. 
El es la vida y la naturaleza, regala un yelmo de oros $y$ diamantes a mis sueños errantes. ${ }^{14}$

Mencionemos la importancia del sonido en dos: "La dulzura del ángelus" y "Nocturno" ("Los que auscultasteis").

Ahora comentemos El canto errante (1907). En la primera poesía, que lleva el mismo título, hay una serie de lugares más bien evocados que descritos. Hay unos pocos colores, y apenas hay idea o emoción (romántica).

De las once poesías bajo el título Intensidad, hay dos dedicadas principalmente a la descripción: "Desde la pampa" y "Visión". En la primera se describen varios aspectos de la pampa, con amplio empleo del color al principio y al fin. La segunda es una escena fantástica y alegórica que representa "el reino de la lira de Dante". ${ }^{15}$ Lo plástico es abundante. En otras dos poesías, "Revelación" y "Tutecotzimi", la descripción es muy importante, aunque quizás no llegue a ser el elemento predominante. También tiene una cierta importancia en "Metempsicosis" y "Momotombo". En las otras cinco poesías hay sólo los acostumbrados elementos aislados.

En las dos partes de "In memoriam" Bartolomé Mitre, "Arbol feliz" y "Oda a Mitre", los toques de color son pocos.

Entre los diez poemas de Ensueño, hay tres en que predomina la descripción: "La bailarina de los pies desnudos", "Vésper" y "La hembra del pavo real". Cada uno es la descripción de una sola cosa, pero el empleo del color es algo restringido. Hay otros tres en que la descripción es importante: "Dream", "La canción de los pinos" y "Hondas". Estos tres constan de series de imágenes diversas, el primero y el tercero de visiones en un sueño y el segundo de varios tipos de pinos. Los cuatro restantes contienen poca descripción.

La sección Lira alerta consiste en veintitrés poesías. Sólo dos, "Soneto para el señor don Ramón del Valle-Inclán" y "Los piratas", se acercan a la pura descripción, aunque el uso del color es muy limitado en ellas. En "Interrogaciones" hay una serie de pequeñas descripciones con bastante color. La descripción es algo importante en otras cuatro poesías: "A un pintor", "Balada en honor de las musas de carne y hueso", "Flirt" y "A una novia". Sólo en la última hay unidad de la cosa descrita, pero la descripción no llega a ser el asunto principal de la poesía. En las otras dieciséis poesías, los toques de color ya son muy raros.

\footnotetext{
14 Poesias, p. 739.

15 Ibid., p. 803.
} 
Ahora veamos Poema del otoño y otros poemas (1910). "Poema del otoño" contiene poquísima descripción. Pasemos a la sección Intermezzo tropical en que hay nueve poemas. De estos nueve solamente los dos primeros, "Mediodía" y "Vesperal", son plenamente descriptivos. Los toques de color son discretos pero poderosos. La descripción es bastante importante en otro dos poemas también, "Canción otoñal" y "Canción", aunque hay muy poco color en el segundo. Los otros cinco contienen poca descripción.

De las cuatro poesías de Varia, la primera, "Santa Elena de Montenegro", y la cuarta, "El clavicordio de la abuela", describen una escena. La primera muestra "escenarios de pesadilla", ${ }^{16}$ aunque con pocos colores. La otra tiene asunto más risueño y también más colores. Las otras dos no of recen descripción.

Ahora el último libro, Canto a la Argentina y otros poemas (1914). "Canto a la Argentina", poema muy largo, contiene algunos paisajes descriptivos, por ejemplo de la pampa ${ }^{17}$ o de la mujer. ${ }^{18}$ Pero las notas de color son raras.

Entre los once Otros poemas, hay dos en que predomina la descripción: "Valldemosa" y "Danzas gymnesianas". El color es de uso restringido en ambos. La descripción es de cierta importancia en "La canción de los osos", particularmente la de los diferentes tipos de osos y de las escenas que los rodean. Sólo de vez en cuando hay un toque de color; pero he aquí un ejemplo admirable:

$$
\begin{aligned}
& \text { A vuestro lado va la gitanilla. } \\
& \text { Brilla } \\
& \text { su mirada de negros diamantes, } \\
& \text { y su boca roja es fresca; } 19
\end{aligned}
$$

En las ocho poesías restantes el color es infrecuente, pero de cuando en cuando aparece un toque de plasticidad. He aquí un ejemplo de "La Cartuja":

$$
\begin{aligned}
& \text { La soledad que amaba Jeremías, } \\
& \text { el misterioso profesor de llanto, } \\
& \text { y el silencio, en que encuentran harmonías } \\
& \text { el soñador, el místico y el santo, }
\end{aligned}
$$

\footnotetext{
16 Ibid., p. 879.

17 Ibid., p. 893.

18 Ibid., pp. $905-907$.

19 Ibid., pp. 938-939.
} 


\begin{abstract}
fueron para ellos minas de diamantes que cavan los mineros serafines a la luz de los cirios parpadeantes

y al son de las campanas de maitines. ${ }^{20}$
\end{abstract}

Ya hemos examinado rápidamente seis libros de poesía rubendariana. Ahota resumamos un poco lo que hemos visto. Tengamos en cuenta, sin embargo, que toda clasificación tiene algo de arbitrario y que nuestras cifras pueden estar sujetas a un cierto margen de error; por lo tanto, del elemento plástico en la poesía de Rubén Darío sólo pretendemos dar una vista muy general.

De los 205 poemas incluidos en los seis libros considerados, hay 38 con asunto plenamente descriptivo, 32 con asunto parcialmente descriptivo y 135 con poca o ninguna descripción. De los 38 en que predomina la descripción, hay 28 que describen una sola cosa o escena y 10 que describen una serie de cosas. De los mismos 38 poemas descriptivos, hay 5 en que el color es predominante, 22 en que el color es importante pero sin llegar a predominar, y 11 en que hay poco color. En los 32 poemas parcialmente descriptivos, suele haber algún color, pero las más veces como elemento menor. De los 135 poemas con poca o ninguna descripción, tal vez 80 (estas cifras son aproximativas) contienen un poco de plasticidad y tal vez 55 ninguna. De modo que de los 205 poemas en cuestión, tres cuartos contienen al menos un poco de plasticidad, la tercera parte son plena o parcialmente descriptivos, y la descripción predomina plenamente en más de la quinta parte.

Ahora una idea muy general de cómo varían los distintos libros. He aquí las proporciones aproximativas: Los poemas plena o parcialmente descriptivos constituyen dos quintos de los poemas de $A z u l$, dos quintos de los de Prosas profanas y otros poemas, un quinto de los de Canios de vida $y$ esperanza, los cisnes, $y$ otros poemas, dos quintos de los de $E l$ canto errante, tres séptimos de los de Poema del otoño y otros poemas, $y$ un tercio de los de Canto a la Argentina y otros poemas. Los poemas plenamente descriptivos constituyen un quinto de $A z u l$, un tercio de Prosas profanas y otros poemas, un décimo de Cantos de vida y esperanza, los cisnes, $y$ otros poemas, un quinto de El canto errante, dos séptimos de Poema del otoño y otros poemas, y un sexto de Canto a la Argentina $y$ otros poemas. Se ve que la proporción de poemas descriptivos llega a su punto más bajo en Cantos de vida y esperanza, los cisnes, y otros poemas, y después vuelve a subir. Lo mismo es verdad de la can-

20 Ibid., p. 919. 
tidad de color. Sin embargo, la proporción de poemas sin plasticidad alguna es mucho más alta en Cantos de vida y esperanza, los cisnes y otros poemas, El canto errante y Poema del otoño y otros poemas, especialmente en los dos últimos, que en $A z u l$ y Prosas profanas $y$ otros poemas.

Hemos dicho que la expresión poética de la belleza sensorial, o sea plástica, fue lo más fundamental del estro de Théophile Gautier. Hemos buscado este elemento en seis libros de poesía de Rubén Darío. Ahora ¿qué conclusión podemos sacar sobre la influencia de Théophile Gautier en Rubén Dario? Primero, concluimos que la expresión de belleza plástica tiene una parte muy considerable en la poesía de Rubén. Pero epodemos estar seguros de que se debe completamente a la influencia de Gautier? La cuestión de influencias literarias siempre ha sido muy espinosa. Gautier sólo fue uno de los varios escritores que emplearon mucha plasticidad en su obra. Rubén no sólo fue un artista muy creador, sino que se inspiró en fuentes muy diversas. Por lo tanto, cualquier afirmación sobre la influencia de Gautier en Rubén Darío debe proferirse con muchas reservas. Sin embargo, nos attevemos a inducir provisionalmente de nuestras observaciones que Théophile Gautier y su escuela del arte por el arte han ejercido, directa o indirectamente, una gran influencia en el empleo que Rubén Darío ha hecho de la belleza plástica, sea por su propio valor estético, sea para reforzar con este valor un contenido abstracto de idea o sentimiento. ${ }^{21}$

University of California,

BRENTON CAMPBELL

\section{Sctnata Bárbara}

21 Algunos otros posibles puntos de influencia son la musicalidad del verse, el vocabưlario poético (incluso términos extranjeros), y el amor sensual. 
